\title{
ASSOCIAÇÃO BRASILEIRA DE ENFERMAGEM
}

\author{
Relatório referente ao 1. Período de Gestão \\ (1976/1980 (19-08-76 a 30-06-77)
}

Ieda Barreira e Castro

RBEn/03

CASTRO, I.B. - Relatório referente ao $1 .^{\circ}$ periodo de gestão 1976/80 (19/8/76 a 30-6-77). Rev. Bras. Enf.; DF, 30 : 356-369, 1977.

\section{INTRODUÇÃO}

A gestão dos negócios da ABEn no período caracteriza-se pela implantação de um novo Estatuto e pela busca de modos e caminhos de a Associação desempenhar seu papel, ao iniciar seu segundo cinquentenário. A Associação abrange a ABEn Central, as Seções e respectivos Distritos, que devem desenvolver suas atividades de modo harmônico e coordenado para a consecução de seus fins. Por este motivo neste relatório à $A D$ é apresentada, embora de modo sumário, a totalidade das realizações da entidade em todas as suas instâncias $\left({ }^{*}\right)$.

Funcionamento das Diretorias e Conselhos Fiscais

As primeiras providências da Presidente da ABEn, "ad referendum" da Diretoria foram as de instituir comissões especiais para a "Redação das Recomendaçōes do XXVIII Congresso Brasileiro le Enfermagem" para a "Redação do novo Estatuto da ABEn" - e para o atendimento ao XVI Congresso Quadrienal do ICN - Tóquio-Japão-77. A Secretária Executiva deste Congresso, Fumie Kobayashi, visitou o Brasil, em agosto de 1976, sendo recebida no Rio de Janeiro pela Presidente da ABEn, pela Secretária Executiva (Clarice Ferrarini), pela Coordenadora da Comissão Especial Herdy de Almeida Vieira, pela Presidente da Seção Rio de Janeiro e pela Prof.a Vilma de Carvalho, ex-colega de curso, nos Estados Unidos, da enfermeira japonesa. Em Brasília foi recebida pela $1{ }^{a}$ Vice e em São Paulo por Anayde e Amália Corrêa de Carvalho e Taka Oguisso.

Paralelamente foi providenciada pela atual Presidente, a ex-Presidente e a Secretária Executiva, juntamente com a Escola Ana Neri, cobertura para a assis-

(*) Os relatórios das Seçōes do AM, PI, PE e MT nāo chegaram a tempo de serem incluídos ou não chegaram de todo. 
tência prestada à Miss Bertha Pullen, convidada especialmente para as comemoraçōes do Cinquentenário da ABEn e hospitalizada devido a acidente sofrido no hotel, até o seu embarque para os Estados Unidos. A ABEn agradeceu oficialmente às suas ex-alunas a dedicação com que acompanharam o restabelecimento de Miss Pullen e à Real Beneficiência Portuguesa e a seus médicos pelas atençōes com que cercaram sua ilustre cliente e pela benevolência na apresentação da conta; Miss Pullen doou à ABEn dois mil cruzeiros, com os quais foi comprada uma baixela de chá de prata, e posteriormente 750 dólares americanos.

Outras medidas iniciais foram o registro do novo Estatuto em cartório, a divulgação das Recomendaçōes do XXVIII Congresso Brasileiro de Enfermagem às Seçōes da ABEn e às autoridades interessadas e a instalação da Secretaria da Associação na sua sede, em Brasília.

A primeira reunião ordinária da Diretoria foi realizada exatamente um mês após à sua posse, isto é, no dia 18 de setembro. Neste dia foi aprovada a indicação do nome da Irmã Maria Tereza Notarnicola para Secretária Executiva da ABEn, em substituição à D. Clarice Ferrarini, que havia pedido dispensa do cargo, devido a problemas particulares e de careira profissional. Foi aprovado um voto de louvor pela dedicação, zelo e competência com que se houve a mesma no desempenho de suas funçōes.

A Diretoria da ABEn Central reuniuse ordinariamente seis vezes, como estabelece o Estatuto, sempre na Sede da ABEn em Brasília, sendo cinco vezes sob a presidência da Presidente da ABEn e uma vez da $1 .^{\mathrm{a}}$ Vice-Presidente, na época Presidente em Exercício. Devido à necessidade de sessōes de trabalhos preparatórios à aprovação de documentos como o Plano Global de Trabalho da Diretoria, o Orçamento-Programa para 1978 e à discussão deste Relatório, a Diretoria de- liberou, a cada reunião, iniciar os trabalhos no sábado, às 13 horas, de modo a permitir que no domingo a sessão se encerrasse em hora que permitisse aos riembros não residentes no Distrito Federal regressarem ao seu Estado no mesmo dia. A freqüência mínima às reuniōes foi de dez membros.

Realizou-se uma reunião extraordinária (em São Paulo), para discussão e aprovação de subsídios pa:a o Anleprojeto de Lei do Exercício Profissional elaborado pelo COFEn.

A Presidente Ieda Barreira e Castro foi substituída pela $1 .^{\text {a }}$ Vice-Presidente Isaura Lopes Godoy nos períodos de novembro a dezembro de 1976, quando aquela viajou aos Estados Unidos, atendendo a convite da OPAS/OMS.

As Diretorias das Seçōes reuniram-se ordinariamente de três (SC) a 20 vezes (DF) e as dos Distritos de cinco (Ribeirão Preto/SP) a 10 vezes (Campinas/SP e Juiz de Fora/MG) e extraordinariamente duas (RS) ,cinco (BA, SP e MG), oito (DF) ou 10 vezes (MA). A Diretoria da Seção da PB não se reuniu no período devido ao afastamento e posterior renúncia de seu Presidente. As Seçōes do CE, RN, PB, AL e os Distritos do Rio e Juiz de Fora não informaram da realização de Assembléias Gerais, conforme manda o Estatuto. Realiízaram Assembléias Estaduais de Delegados as Seçōes RJ, RS, MG e GO.

As Seçōes da PB, AL, SE, RJ (Seção e Distritos), SP (Seção e Distritos), RS, GO, MT e DF não informaram sobre verfiicação de contas pelo respectivo Conselho Fiscal.

A Diretoria e o Conselho Fiscal da ABEn até junho de 1977 não sofreram alteraçōes em sua composição; entretanto, nas Seçōes da PB, RN, RS e MG, 20 for cento ou mais dos membros da Diretoria e/ou Conselho Fiscal foram ou estão para ser substituídos. 
Dos assuntos pendentes na ocasião da posse das novas Diretorias, apenas a ABEn Central (duas comissōes especiais) e na Seção Minas Gerais os assuntos eram técnicos. Todas as outras Seçōes indicaram problemas administrativos.

Comissōes Permanentes da ABEn Central

Atividades Científicas e Documentação (CACID) - Esta Comissão está constituída por duas sub-comissōes:

1. Atividades Científicas, com a finalidade de planejar a organização do CEPEn, atualmente com sede em Ribeirão Preto, São Paulo. O Regimento Especial do CEPEn encontra-se em fase de discussão. Foi elaborado um questionário destinado às escolas de enfermagem para o levantamento de dissertaçōes e teses aprovadas, com vistas à organização de um "Catálogo de Teses de Enfermeiras Brasileiras". O fichamento dos trabalhos já foi iniciado.

2. Documentação, com as atribuiçōes da antiga Comissão de Documentação e Estudos, atualmente com sede na cidade de São Paulo.

Fui realizado o Levantamento sobre a Formação de Recursos Humanos de Enfermagem nos cursos de graduação, técnico e auxiliar, com a colaboração das respectivas Comissỏes Estaduais. Destacaram-se neste aspecto, por mais eficientes, as Seçōes RN, SE, BA, RJ e MG.

Em andamento, com o auxílio da Secretaria Executiva, a revisão do Arquivo da ABEn Central, com a finalidade de seleção e classificação do material com valor documentário.

Declararam haver trabalhado integradamente à essa comissão da ABEn, as Seçōes do RN, SE, BA, RJ, SP, PR, SC, RS e MG.

EDUCAÇAO - A atividade mais marcante desta Comissão foi a de assessoramento às autoridades governamentais e outras instituiçōes, para o que participou da elaboração dos seguintes locumentos:

- padōres mínimos para o funcionamento de cursos de habilitação e qualificação em Enfermagem (Técnico e Auxiliar) com o COREn/RJ.

- subsídios para o Departamento Estadual de Ensino Supletivo, no que se refere a normas, programas e provas para concursos, para auxiliar e técnico de Enfermagem, com o COREn/RJ e com o Coordenador Setorial da Coordenação do Ensino Supletivo.

- exposição de motivos para a criação e empregos de técnicos de Enfermagem no Serviço Público Federal, com a Presidente da ABEn e outras colaboradoras.

- exposição de motivos sobre a Resolução do INPS n.o 036.36 e outras para cumprimento do Decreto Presidencial n. ${ }^{\circ}$ 75.778, sobre estágio de alunos de Enfermagem em unidades daquele Instituto, com a Presidente da ABEn e diretoras de Escolas de Enfermagem do Estado do Rio de Janeiro e de Niterói.

- subsídios para o Caderno Vestibular de 1978, do jornal "O Globo".

Além disso promoveu entrevista com - Diretor do Departamento de Ensino Supletivo do MEC," à qual compareceu a Presidente da ABEn e a Prof. ${ }^{\text {C Cecília }}$ Pêcego Coelho, Diretora da Escola Ana Neri/UFRJ e membro da Comissão.

Orientou candidatas à revalidação de diploma de enfermeiro e de técnico; deu informaçōes sobre as condiçōes de trabalho no Brasil para enfermeiros estrangeiros; prestou assessoria em questōes relativas à elaboração de currículos e à História da Enfermagem e colaborou no curso de atualização "Implementação das Prescriçōes Medicamentosas" promovido pela Seção Rio de Janeiro, durante a Semana da Enfermagem. 
O Prêmio "Marina de Andrade Rezende", destinado a estudantes de Enfermagem foi concedido à aluna Tânia Mara Cansian, da Universidade Católica do Paraná.

As Seçōes do MA, SE, BA, SP, SC, GO e Distrito de Volta Redonda/RJ, informaram haver trabalhado de modo integrado com a Comissão de Educação da ABEn Central.

\section{FINANÇAS}

Conforme disposição estatutária, a Coordenação da Comissão de Finanças compete à 2. ${ }^{\text {a }}$ Tesoureira.

$\mathrm{Na}$ atual Diretoria a $1 .^{\mathrm{a}}$ Tesoureira reside em São Paulo e por isto foram delegadas à 2. ${ }^{\text {a }}$ Tesoureira, residente em Brasília, as seguintes atividades: pagamento das contas da sede (impostos, taxas, etc.), dos salários do pessoal da $A B E n$, recolhimento dos encargos sociais (INPS, FGTS e outros), contratação e demissão de funcionários, recolhimento de "per capita" da Seção DF, do valor mensal referente aos convênios da ABEn Central com a ABEn Seção DF, com o COFEn e COREn/DF, com o COFEn e COREn/RJ. Isto obriga à elaboração mensal de Livro-Caixa e de apresentação e demonstração da recelta-despesa da sede em Brasília. Foi aberta contacorrente em agência do Banco do Brasil, em Brasília; e a 2.a Tesoureira e a 1.a Vice-Presidente, também residente em Brasilia, foram autorizadas a movimentá-la.

Como os membros do Conselho Fiscal também residem em Brasília, a 2. ${ }^{\text {T }}$ Tesoureira tem-nos atendido para a verificação das contas.

Por todo o exposto o desenvolvimento das atividades relacionadas à Comissão de Finanças ficou prejudicado. Entretanto, foram envidados alguns esforços para a obtenção de recursos para a ABEn, sobressaindo a solicitação à
NOVACAP para a execução dos trabalhos de calçamento da rua, pista de entrada de carros e estacionamento da sede, para o que colaborou a colega Maria Aglaé B. Costa. Foram vendidos 984 livros e feita aplicação de capital em letras de câmbio.

Sete Seções (PA, CE, RN, BA, SC, RS e MG) informaram haver trabalhado integradas à Comissão de Finanças da ABEn Central. Como esta desenvolveu poucas atividades, supōe-se haver sido a mesma confundida com a Tesouraria.

LEGISLAÇAO - Esta Comissão, além de atividades de representação da $A B E n$, de orientação das colegas dos Estados sobre processos em tramitação, empenhou-se principalmente na atualização do livro "Legislação de Enfermagem". Fol feita a publicação da revista "Documenta", desde dezembro de 1972 a dezembro de 1976 e a assinatura de 1977 a 1980 e dos "Anais do Congresso", desde 1972, e foi, constituída uma equipe para a seleção do material de interesse para a Enfermagem.

Três Seções (MA, SP e SC) e o Distrito de Volta Redonda/RJ Informaram haver trabalhado integradas a essa Comissão.

\section{PUBLICAÇÓES E DIVULGAÇÃO -} Esta Comissão formou quatro equipes de trabalho, a saber:

I - REBEn - A edição do número relativo aos temas oficiais do XXVIII Congresso Brasileiro de Enfermagem sofreu considerável atraso, devida à oferta do Ministério da Previdência e Assistência Social de imprimi-lo o que não se concretizou. Até o terceiro trimestre as ediçōes deverão estar em dia.

A REBEn tem sido expedida para todos os órgãos internacionais de enfermagem e associaçōes nacionais filiadas à FEPAEn. Tem sido feito intercâmbio com o "American Journal of Nursing". Foi enviada uma coleção 1976 e os nú- 
CASTRO, I.B. - Relatório referente ao $11^{\circ}$ periodo de gestāo 1976/80 (19/8/76 a 30-6-77).

Rev. Bras. Enf.; DF, $30: 356-369,1977$.

meros de 1977 para o "Index Internacional de Enfermagem", para fins de catalogação.

A Gerência da Revista continua com a Ir. Maria Tereza Noternicola, que apesar de estar residindo em Brasilia e de acumular os cargos de Secretária Executiva, de Administradora da Sede da ABEn Central e de membro das Comissões de Finanças e de Legislação, prontificou-se a continuar com o encargo, enquanto se treina outra pessoa. A compra do papel em São Paulo, e a expedição de revistas que vão para as Seções (estão a cargo da gráfica, no Rio), em número de 210 para o Brasil e 88 para o exterior, são algumas das atividades desenvolvidas pela Gerente.

II - Página do Estudante - Esta equipe organizou e divulgou um Concurso de Trabalhos Científicos para a Página do Estudante, a ser realizado ainda em 1977. O prêmio será uma assinatura extra da REBEn, por 2 anos.

III - Boletim Informativo (BI) Sua edição tem sido mensal, embora com alguns atrasos. A tiragem foi aumentada de 1.000 para 1.500 exemplares. A meta é atingir o número total de assocłados. Foram expedidos pela Secretaria 20 mil e 40 BI para o Brasil e 360 para 0 exterior.

IV - Outras Publicações - Elaborado plano para 1978 (ver orçamento-programa).

As Seções de SE, BA, RJ, SP, PR, SC, RS e MG declararam haver trabalhado integradas à essa Comissão da ABEn Central.

SERVIÇO DE ENFERMAGEM - Esta Comissão desenvolveu poucas atividades. A Coordenadora reside em Curitiba, e além disso, se ressente da falta de uma tradição de realizações da ex-Comissão de Assistência. Entretanto, promoveu, junto com o COFEn/PR, um Seminário sobre Código de Deontologia de Enfermagem e tem mantido correspondência com colegas estrangeiras interessadas em trabalhar no Brasil.

As Seções do PR e de SC informaram haver trabalho integradas a essa Comissão da ABEn Central.

\section{COMISSOES PERMANENTES ESTADUAIS}

As Comissões de Atividades Científicas e Documentação, de Educação e de Publicações e Divulgação foram as que parecem ter melhor correspondido aos esesforços de coordenação das respectivas Comissões da ABEn Central.

As Comissões de Educação foram de modo geral muito mais ativas do que as demais na promoção de atividades técnico-científicas e culturais. O fato sugere haver uma interpretação errônea de que aquelas atividades são de competência exclusiva da Comissão de Educação, quando na verdade todas as comissões devem promover atividades de tal natureza.

O tema mais abordado (4 vezes) foi o "Processo de Enfermagem". A "Pesquisa em Enfermagem", "Enfermagem do Trabalho", "COFEn/COREn" e "Equipe de Saúde" foram mencionados por mais de uma seção.

As Seções que promoveram mais de dez temas diferentes foram PA e RJ, entretanto praticamente todas as Seções promoveram atividades dessa ordem.

A dificuldade mais mencionada pelas Seções é a falta de tempo por parte dos membros da Diretoria e/ou da classe em geral para colaborar com a Associação (PA, CE, RN, SE, BA, SP, RS e MG). Outras dificuldades apontadas foram as de melhorar as fontes de renda como anuidades, venda de livros, etc. (Seção RN e RS), distribuição deficiente das Revistas (BA e RS), falta de definição das atribuições das Coordenadoras (PR), falta de intercâmbio com a ABEn Central e "per capita" enviado à mesma muito alto (RS). 
CASTRO, I.B. - Relatório referente ao $1 .^{\circ}$ período de gestāo 1976/80 (19/8/76 a 30-6-77).

Rev. Bras. Enf.; DF, $30: 356-369,1977$.

\section{ATIVIDADES DE APOIO AS DIRETORIAS}

Secretaria - Desde fevereiro a Secretaria Executiva da ABEn Central passou a residir em Brasília, o que possibilitou a mudança da Secretaria e do Arquivo da ABEn Central, até então na cidade de São Paulo, para a sede.

A Secretaria foi equipada para mecanografia e duplicação.

No momento o Arquivo encontra-se em reorganização. Além da Secretária Executiva, a ABEn Central conta com um escrevente-datilógrafo. A correspondência expedida foi a seguinte:

Brasil Exterior Total

$\begin{array}{crrrr}\text { Cartas } \ldots \ldots \ldots \ldots & 358 & 32 & 390 \\ \text { Circulares (17) } \ldots & 571 & - & 571 \\ \text { Ofícios } \ldots \ldots \ldots \ldots & 58 & 2 & 60 \\ \text { Total } \ldots \ldots \ldots \ldots & 987 & 34 & 1.021\end{array}$

A Secretária Executiva assistiu a todas as reuniões ordinárias e extraordinárias da Diretoria. Acompanhou a $1 .^{\mathrm{a}}$ Vice-Presidente nas reuniōes do Conselho Diretor da FEPAEn e no Congresso Fanamericano, realizados em Buenos Aires. Viajou três vezes a Santa Catarina para atender a assuntos ligados ao XXIX Congresso Brasileiro de Enfermagem.

Quanto às Seções Estaduais, apenas quatro delas (CE, SE, SP e DF) contam com secretária executiva (enfermeira). Sete outras (MA, BA, RJ, SC, RS, MG e GO) contam com secretárias que são enfermeiras, nas Seções do PA, CE, PB, AL e BA e nos Distritos de Niterói e Volta Redonda/RJ e Araraquara/SP, a Secretaria está a cargo de um dos membros da Diretoria.

Vale mencionar que as Seções do PA e do PR utilizaram o trabalho de estudantes de enfermagem para o desenvolvimento das atividades da Secretaria, o que parece ser um excelente meio de iniciá-los na vida associativa.

A maioria absoluta dos questionários referentes às atividades das Seções foi respondida pela respectiva Presidente.

Administração da Sede da ABEn Central - A sede encontra-se muitíssimo bem cuidada, sempre limpa e em ordem. A instalação elétrica provisória foi substituída, sendo que no Salão Nobre, Sala da Presidente e Sala de Reuniōes da Diretoria foram colocadas luminárias mais decorativas. Também foi instalada iluminação na parte externa do prédio e nu jardim. Foi aprovada a construção da casa do zelador, e de um depósito, somando $90 \mathrm{~m} 2$ de área e orçado em 200 mil cruzeiros. Atualmente este funcionário mora em um barraco de madeira nos fundos do terreno. O calçamento da rua, pista de entrada e estacionamento está sendo pleiteado, através a Comissão de Finanças, junto à NOVACAP. As próximas metas são a montagem do auditório, e a instalação de dispositivos que aumentem a segurança do prédio contra roubos. No momento temos contrato de vigilância noturna com firma especializada.

Implantação do Sistema de OrçamentoPrograma - A contribuição da 2.a Secretária, Dulce de Castro Mendes, possibilitou à atual Diretoria a aceitação imediata de duplo desafio. 0 de ao mesmo tempo em que, pela primeira vez uma Diretoria da ABEn Central apresenta à aprovação da $A D$ um plano de trabalho e um orçamento, fazê-lo sob a forma de orçamento-programa. Além disso, esse membro da Diretoria prontificou-se a coordenar um seminário sobre o assunto para Presidentes e Tesoureiros de Seções.

REPRESENTAÇAO DA ABEn JUNTO A INSTITUIÇOESS E AUTORIDADES DE AMBITO NACIONAL E INTERNACIONAL

- Federação Panamericana de Enfermeiras/os (FEPAEn) realizou Conse- 
lho Geral nos dias 14, 15 e 16 de outubro de 1976 e seu IV Congresso, nos dias 18 a 22 do mesmo mês. Representaram a ABEn nesses eventos a $1 .^{\mathrm{a}}$ Vice-Presidente Isaura Lopes Godoy, a Secretária Executiva Ir. Maria Tereza Notarnicola e a Dra. Judith Feitosa de Carvalho, que relatou o trabalho de sua autoria "A Enfermeira/o no Processo de Desenvolvimento Social".

- Conselho Internacional de Enfermei$\operatorname{ras}$ (CIE/ICN).

Tendo em vista as eleiçöes para a Diretoria do Conselho a serem realizadas durante a reunião do Conselho de Representantes Nacionais (CRN), foi indicado o nome da Prof. a Vilma de Carvalho como candidata a "Área Member" da América Latina, tendo a mesma obtidc os votos de seis paises.

Representaram a ABEn no CRN e no XVI Congresso Quadrienal, realizado a seguir, a $1 .^{\mathrm{a}}$ Tesoureira Dra. Taka Oguissu e a colega Dorotee Volkers, da Seção de São Paulo.

Compareceram a esse congresso internacional 150 enfermeiros, dos Estados de São Paulo, Rio de Janeiro, Minas Gerais, Ceará, Goiás, Santa Catarina, Pernambuco e Brasília, todos com dispensa do ponto e do pagamento da taxa de $16 \mathrm{mil}$ cruzeiros para viagens ao exterior.

- Comitê Internacional Católico de Enfermeiras e Assistentes Médico-Sociais (CICIAMS).

Tendo em vista a realização de eleiçōes para a Diretoria do CICIAMS e a decisão dá Dra. Amália Corrêa de Carvalho, atual Vice-Presidente para a América do Sul de não concorrer à reeleição, a Diretoria, por solicitação daquela entidade, estuda no momento a conveniência de apresentar outra candidata.

- Organização Internacional do Trabalho (OIT/ILO).
Foi convidada para representar a Associação na reunião anual da OIT, realizada em Genebra, em maio do corrente ano, a mesma representante do COFEn, Prof. Maria Rosa de Souza Pinheiro. Entretanto, o convite não pôde ser aceito por estar a conselheira representando oficialmente o Ministério do Trabalho, o que a impedia de, ao mesmo tempo, representar uma associação particular.

- Associação Brasileira de Escolas Médicas (ABEM).

Apresentou trabalho no XIV Congresso Brasileiro de Educação Médica, realizado de 17 a 19 de novembro de 1976 na cidade do Rio de Janeiro, por indicação da ABEn, a Prof.a Maria Nilda de Andrade, da UFPE, que contribuiu com 0 tema "Integração Docente-Assistencial".

- Sociedade Brasileira para o Progresso da Ciência (SBPS).

Continua como representante da ABEn a Dra. Wanda de Aguiar Horta, que promoveu no último congresso daquela Associação um debate sobre "Histórico do Paciente".

- Ministério da Saúde (MS).

Conforme resolução da $\mathrm{AD} / 76$, foi entregue ofício apresentando exposição de motivos para a criação de um órgão central de enfermagem naquela instituição. A solicitação não teve boa aceitação por não ser compativel com as diretrizes gerais adotadas na reforma administrativa desse Ministério, que obedeceu ao sistema de departamentalização por atividades, atribuidas a equipes multiprofissionais, estando, entretanto a enfermagem muito bem representada nos seus vários setores.

- Ministério da Previdência e Assistência Social (MPAS).

A Presidente da ABEn, acompanhada pela Dra. Maria Ivete Ribeiro de Olivei- 
rá, fez visita de cortesia ao Dr. José Osório Reis, da Secretaria de Moderntzação do MPAS, tendo conversado sobre a atuação da ABEn junto aos órgãos daquele Ministério.

\section{- Instituto Nacional de Previdência} Social (INPB).

A Presidente da ABEn e a Coordenadora de Educação, junto com as diretoras das Escolas de Enfermagem da UFRJ, UERJ, FEFIERJ e PUC/RJ levaram ao Presidente Reinhold Stephanes exposição de motivos solicitando alteraçōes das normas estabelecidas por aquele Instituto para o estágio de alunos em serviços de saúde da previdência, que entre outros inconvenientes, impedem 0 acompanhamento dos alunos pelos professores.

Nessa oportunidade foi entregue documento solicitando a criação de uma Coordenação de Enfermagem naquele Instituto, conforme resolução da $\mathrm{AD} / 76$.

\section{- Ministério da Educação e Cultura (MEC).}

Departamento de Ensino Supletivo Visita de cortesia da Presidente da ABEn, junto com a diretora da Escola Ana Neri (membro da Comissão de Educação da ABEn Central) e da Prof.a Luzia Aparecida Costa, ao Prof.o Leonardo Gomes de Carvalho Leite Neto, para tratar de assuntos relacionados aos exames de suplência profissionalizante.

- Departamento da Administração do Pessoal Civil (DASP).

Fol encaminhado documento, elaborado por Comissão Especial, expondo os motivos pelos quais há a necessidade urgente da criação de cargos e empregos para técnico de Enfermagem no serviço Público Federal.
- Conselho Federal de Enfermagem (COFEn).

Em reuniāo extraordinária, a Diretoria discutiu e aprovou os subsidios elaborados por Comtssão Especial, para - aperfeiçoamento do anteprojeto do COF'gn para substituição da Lei do Exercício Profissional (Lei 2.604/55).

\section{-Congresso Nacional.}

Visita de cortesia da Comissão de Legislação aos membros daquela Casa, tendo em vista a divulgação da Semana da Enfermagem.

\section{REPRESENTAÇAO DAS SEÇOES}

As Seçōes da ABEn se fizeram representar com mais freqüência junto às associaçōes de classe (CE, BA, RJ - Rio e Volta Redonda, SP, SC, RS e DF), às Secretarias Estaduais de Saúde, de Educação e/ou do Trabalho (CE, AL, SE, RJ - Volta Redonda, RS e SP), às autoridades municipais (RJ - Volta Redonda - SP e Araraquara, SC e RS), às Escolas de Enfermagem e/ou Universidades (BA, PR, SC, RS e (OO), aos serviços de saúde (BA, SP - Araraquara, RS), às instituiçōes previdenciárias (SPCampinas, DF), às associaçōes beneficentes (RJ-Niterói) e às autoridades legislativas (DF).

A forma mais comum de contribuição dada pelas Seçōes $e$ Distritos a instituiçōes, autoridades e órgãos de classe fol a de assessoria (a Universidades, Escolas, Secretarias de Educação) - CE, RJ-Volta Redonda, SP, PR, RS, DF e GO. Serviços como participação em campanha da vacinação (RJ-Volta Redonda), recrutamento, seleção e treinamento de pessoal (SP-Araraquara), planejamento de exames (GO e RS) também foram prestados. Cooperaram sob a forma de atividades didáticas as Seçōes do MA, BA, SC e RS. 
CASTRO, I.B. - Relatório referente ao 1.’ periodo de gestão 1976/80 (19/8/76 a 30-6-77).

Rev. Bras. Ene; DF, 30 : 356-369, 1977.

Cooperam com o COREn local as Seçōes do PA, CE, RN, PB, BA, RJ-Rio e Volta Redonda, SP-São Paulo, Campinas e Araraquara, SC, RS, MG, DF e GO.

\section{CONGRESSOS BRASILEIROS DE ENFERMAGEM}

Recomendaçōes do XXVIII Congresso Brasileiro de Enfermagem:

Foram enviados ofícios a todas as autoridades mencionadas nas recomendaçōes. Além disso, fol feita ampla divulgação das mesmas às Seçōes, Distritos e Escolas de Enfermagem.

\section{Recomendaçōes dirigidas à ABEn Central:}

Recomendaçōes 10. a, b - "que estude a possibilidade de sistematizar o processo de divulgação de suas atividades junto ao corpo discente das escolas de enfermagem".

Este trabalho foi iniciado por meio de notícias no BI. Entretanto deverá ser elaborado no próximo período da gestão um modelo de programa como sugestōes às Seçōes.

Recomendaçōes 12. a, b - "que forneça subsídio ao grupo de trabalho em funcionamento no DAU/MEC, no que concerne a problemas curriculares, principalmente quanto ao assunto habilitaçōes específicas".

A Presidente da ABEn e a Coordenadora da Comissão de Publicaçōes e Divulgação participaram de reunião promovida pelo Departamento de Assuntos Universitários do MEC, com a participação de professoras de várias regiōes do país, que elaboraram documento a respeito.

\section{Seçōes da ABEn:}

As Seçōes Estaduais que declararam haver trabalhado sobre um maior nú- mero de Recomendaçōes do XXVIII Congresso Brasileiro de Enfermagem foram as do PR, que citou onde delas e SC, qus citou sete.

Dentre as recomendaçōes, as que mereceram mais atenção por parte das Seçōes foram as referentes à participação do estudante na vida associativa (recomendaçōes de número 10) mencionadas pelas Seçōes do PA, MA, CE, RN, PB, BA, RJ, SP, PR, SC, RS, MG e DF) e a suplência profissionalizante (recomendaçōes de número 9) mencionadas pelas Seçōes do MA, AL, BA, RJ, (Seção) e Distrito de Volta Redonda, PR e RS. As Seçōes do PA, RJ-Volta Redonda, PR, SC, MG (Seção) e Distrito de Juiz de Fora e GO divulgaram as recomendaçōes às autoridades e instituiçōes interessadas.

Quanto ao desenvolvimento do espírito associativo entre os estudantes de Enfermagem, os meios escolhidos pelas Seçōes para atingir este objetivo foram bastante variados, sendo os mais citados as atividades didáticas (palestras, cursos, etc.) citadas pelas Seçōes do MA, CE, BA, RJ-Niterói e Volta Redonda, SPAraraquara, PR, SC, MG-Juiz de Fora; a participação dos estudantes nas comemoraçōes da Semana da Enfermagem foi citada pelas Seçōes SP-Araraquara, PR e DF; as reuniōes com alunos e as entrevistas e visitas à Seção foram citadas respectivamente pelas Seçōes do RN e PR. A colaboração na atividade de angariar fundos para a formatura foi citada pela Seção do PA e a promoção de jogos desportivos pela Seção do MA.

XXIX Congresso Brasileiro de Enfermagem

A Diretoria aceitou o oferecimento da Seção de Santa Catarina para organizar o conclave. Para a realização do XXIX Congresso Brasileiro de Enfermagem foram criadas três Comissōes Especials:

Comissão Executiva, coordenada pela Presidente da Seção SC; Comissão de 
CASTRO, I.B. - Relatório referente ao $1 .^{\circ}$ periodo de gestāo 1976/80 (19/8/76 a 30-6-77). Rev. Bras. Ene.; DF, 30 : 356-369, 1977.

Temas, coordenala pela Dra. Tereza de Jesus Sena e Comissão de Recomendaçōes, coordenada pela Presidente da Seção DF.

Durante o Congresso será outorgado à Dra. Amália Corrêa de Carvalho, o título de Sócia Honorária da ABEn, conforme resolução da $\mathrm{AD} / 76$.

Foi solicitada e concedida a dispensa de ponto das enfermeiras das repartiçōes públicas federais e autárquicas, para seu comparecimento ao Congresso.

\section{SEMANA DA ENFERMAGEM}

Através a Comissão de Legislação, a Diretoria da ABEn Central enviou aos membros do Congresso Nacional cartōes alusivos à Semana da Enfermagem.

Todos os membros da Diretoria participaram das comemoraçōes da Semana da Enfermagem nas suas respectivas Seçōes.

As Seçōes do PA, MA, CE, RN, SE, BA, RJ, SP, PR e DF organizaram reuniōes sob a forma de encontros, jornada ou "semana". Como parte integrante ou não dessas reuniōes foram desenvolvidas atividades didáticas pelas Seçōes do MA, CE, PB, AL, RJ-Volta Redonda, SP-São Paulo, Ribeirão Preto, Araraquara, PR, RS, GO, MG-Juiz de Fora. Foi providenciada a celebração de missas e cultos pelas Seçōes do RN, AL, SE, RJ, SP-São Paulo e Araraquara, PR, MG-Juiz de Fora, GO e DF.

Houve programas sociais (almoço, jantar, coquetel), nas Seçōes de AL, SE, RJVolta Redonda, SP-Ribeirão Preto e Araraquara, PR, RS, MG-Juiz de Fora e DF.

Foram pomovidas solenidades no MA, AL, SP-São Paulo e Araraquara, PR, MG-Juiz de Fora, atividades artísticas nas Seçōes do CE e PR e desportivas na de MG-Juiz de Fora. Fol feita divulgação pela imprensa nas Seçōes da RN, BA, SP-Araraquara, SC, RS e DF. A Seção RJ promoveu romaria ao túmulo de Lays Netto dos Reis.

\section{OUTRAS ATIVIDADES TECNICO- CIENTIFICAS E CULTURAIS}

A Presidente da ABEn compareceu ao programa de entrevistas J. Silvestre, na TV-Tupi, como entrevistada principal, acompanhada pelas convidadas especiais Dra. Nalva Pereira Caldas (Pres. COREn/RJ), Maria de Jesus Silva (Pres. Associação Profissional/RJ), Prof.a Elvira de Felice Souza (Pres. ABEn/RJ), Prof. Cecília Pêcego Coelho (Diretora da Escola Ana Neri), e Prof.a Alayde Bittencourt (Diretora da Escola de Enfermagem da UERJ). O programa teve a duração de uma hora, foi transmitido a cores e constituiu-se em excelente divulgação da Enfermagem, pois os debates foram de alto nivel.

A convite do Projeto Rondon a $1 .^{\mathrm{a}}$ Vice-Presidente coordenou um Seminário no Departamento de Enfermagem da Universidade do Vale do Acaraú, Sobral, CE.

A coordenadora da Comissão Serviço de Enfermagem participou da promoção de um Seminário sobre Código de Deontologia de Enfermagem, em Curitiba, junto ao COREn local.

Dentre as atividades técnico-científicas e culturais promovidas pelas Seçōes cestacaram-se os cursos e/ou treinamentos. Neste particular destaca-se a Seção de São Paulo, que realizou dezessete dessas promoçōes. As Seçōes da BA e RJ-Volta Redonda promoveram três dessas atividades, as Seçōes do PA, MA, SE e RS promoveram duas e RN, SP-Ribeirão Preto, Araraquara, PR e GO promoveram um curso ou treinamento.

As Seçōes do PA, MA, CE, RN, SE. BA, RJ, SP, PR e RS promoveram encontros e/ou jornadas, sendo que a do CE promoveu oito, SP três, o PR duas e as restantes uma.

A Conferência também foi outro tipo de atividade promovida pelas Seçōes do MA (oito), PR (duas), RS (três), RN, BA, SP (uma cada) e CE (sem número). 
CASTRO, I.B. - Relatório referente ao $1 .^{\circ}$ periodo de gestāo 1976/80 (19/8/76 a 30-6-77).

Rev. Bras. Enf.; DF, $30: 356-369,1977$.

As Seçōes do MA, CE e GO promoveram seminários.

Apenas as Seçōes da BA, RJ e MG declararam haver desenvolvido atividades relacionadas a levantamento, quando na verdade um número muito maior de Seçōes colaborou com a Coordenação de Atividades Científicas e Doc. da ABEn Central. A Seção do RS, informou haver promovido pesquisa sobre "Enfermagem e Comunidade".

As Seçōes do PA. MA, CE, AL, RJ, MGJuiz de Fora, e DF realizaram palestras, mas não especificaram o número, com exceção do Distrito de Volta Redonda-RJ que realizou quatro.

\section{Comissōes Especiais}

Funcionaram junto à Diretoria da ABEn Central as seguintes Comissões Especiais:

1. Comissão Especial para a Redação das Recomendaçōes do XXVIII Congresso Brasileiro de Enfermagem, integrada pela $1 .^{\text {a }}$ Vice-Presidente da atual Diretoria e por Adalgisa Vieira Mattos € Vivina Lanzarini de Carvalho, respectivamente Coordenadora e membro da Comissão de Recomendações do citado Congresso.

2. Comissão Especial para a Redação do novo Estatuto da ABEn, composta pela Presidente, 1.8 Vice-Presidente $\mathrm{e}$ Dra. Amália Corrêa de Carvalho, autora do anteprojeto, da Diretoria anterior, apresentado à A.D.

3. Comisão Especial para a Carreira de Enfermeiro nas Forças Armadas; o trabalho dessa Comissão, constituída há duas gestões, foi avaliado e em virtude das opiniōes desfavorávels de enfermeiros que trabalham em hospitais militares, a Diretoria deliberou suspender temporariamente as atividades da comissão.

4. Comissão Especial para o Código de fica do CIE (ICN) em língua portuguesa.
Esta Comissão funcionou na gestão anterior, faltando compatibilizar a tradução feita no Brasil com aquela feita em Portugal.

5. Comissão Especial para o XVI Congresso Quadrienal do ICN.

Esta Comissão, coordenada por Herdy de Almeida Vieira e integrada por Nair Cruz, Margareta Luce de Delgado e Maria Amélia Rangel fez a divulgação desse Congresso para todo o Brasil e manteve entendimentos com a companhia de turismo encarregada da excursão.

6. Comissão Especial para a elaboração de subsídios à Diretoria da ABEn, para o estudo do anteprojeto da nova lei do exercício profissional, elaborado pelo COFEn.

Esta Comissão fol coordenada pela Presidente da ABEn e integrada pelas Professoras Vilma de Carvalho, Elvira de Felice Souza e Maria Dolores Lins de Andrade.

7. Comissōes Especiais para a Enfermagem da Previdência Social.

Inicialmente foi criada a C.E. para o Serviço de Enfermagem do INPS, coordenada pela Prof.a Elvira de Felice Souza, que elaborou exposição de motivos jara a criação de uma Cocrdenação de Enfermagem naquele Instituto. Com vistas à criação no Instituto Nacional de Assistência Médica da Previdência Social IINAMPS), que englobará os serviços de saúde de todos os órgãos previdenciários federais. fol criada uma segunda Comissão Especial para acompanhar a estruturação do novo órgão e trabalhar em prol da criação de uma Coordenação de Enfermagem no novo órgão. Essa segunda comissão, ainda em atividade, tem como coordenadora Terezinha Lírio do Patrocínio.

8. Comissão Especial para a elaboração de anteprojeto do Regulamento Geral da ABEn.

Esta Comissão é coordenada pela Prof.a Leônia Machado Borges. A coordenadora 
da CACID forneceu subsidios referentes à competência das Comissões Permanentes.

9. Comissão Especial para a elaboração da exposição de motivos sobre a necessidade da criação de cargos e empregos para o técnico de Enfermagem no Serviço Público Federal.

Esta Comissão foi coordenada pela Presidente e integrada pela Coordenadora da Comissão de Educação, Dras. Haydée Guanaes Dourado e Vivina Lanzarini de Carvalho, membros da Comissão de Educação.

10. Comissão Especial para o estudo de viabilidade de elaboração de uma escala proporcional para o pagamento do "per capita" à ABEn Central, integrada pela 1. ${ }^{\mathrm{a}}$ Tesoureira, pela Coordenadora da Comissão de Publicidade e Doc. e pela Gerente da REBEn.

11. Comissões Especiais para o XXIX Congresso Brasileiro de Enfermagem:

- Comissão Executiva, integrada por

Nelcy T. Coutinho Mendes (Presidente), Lúcia Herta Rockenbach (Secretária) e João Flávio Vendrúscolo.

Os trabalhos dessa Comissão foram acompanhados pela Secretária Executiva da ABEn.

- Comissão de Temas, integrada por Dra. Teresa le Jesus Sena (Coordenadora), Berenice Xavier Elsas e Maria Albertina Braglia Pacheco.

- Comissão de Recomendações, integrada por Antonia Xavier da Silva (Coordenadora), Adalgisa Vieira Matos, Vilma de Carvalho, Maria José Schimidt e Maria de Lourdes Ortiz.

A maioria das Seções da ABEn constituíram Comissões Especiais para determinados encontros culturais. Assim as Seçōes do PA, MA, RN, PR, RS, MG (Seção) e Distrito de Juiz de Fora criaram comissões especiais para a Semana da Enfermagem; as Seções da BA e do DF, para a organização de Encontros; a Seção do PR, para a organização de uma jornada; e a Seção do MA para estudos da viabilidade de hospedar um dos próximos Congressos; a Seção de SP, para a organização do Congresso da Federação Mundial de Enfermeiras/os NeuroCirúrgicos/as; SP-Araraquara, para a organização do Curso de Auxiliar do Trabalho; e a do RS, para o estudo do currículo do Curso de Auxiliar de Enfermagem de $2 .^{\circ}$ gráu.

As Seções do RJ e PR formaram comissões para a realização de eleições e o Distrito do Rio de Janeiro, para a elaboração de anteprojeto do Regimento Interno do Distrito.

As Seções do PR e MG-Juiz de Fora constituíram comissões para o estudo do anteprojeto da Lei do Exercício Profissional, elaborado pelo COFEn.

A Seção do SE organizou comissão para as comemoraçōes do Natal e a do PR para relações públicas.

A Seção de SP também criou uma Comissão Pró-Nova Sede, outra de apoio às Comissōes Permanentes (formada por enfermeiras aposentadas). SP-Araraquara constituiu comissão para o recrutamento de novos sócios.

A Seção do PR organizou também comissão para a criação e implantação de um jornal.

A Seção de AL formou comissão para tratar da suplência profissionalizante e a Seção de GO uma para o Estudo da Situação do Enfermeiro e do Auxiliar de Enfermagem no INPS.

\section{SERVIÇOS PRESTADOS DIRETAMENTE AS ASSOCIADAS}

A Diretoria da ABEn Central, conforme reza o Estatuto, providenciou a abertura de conta especial para a Casa da Enfermeira em caderneta de poupança e o recolhimento de $2 \%$ da renda bruta da Associação.

Todas as Seções e Distritos que responderam ao questionário declararam distribuir às associadas as publicações 
CASTRO, I.B. - Relatório referente ao 1.॰ periodo de gestão 1976/80 (19/8/76 a 30-6-77). Rev. Bras. Enf.; DF, 30 : 356-369, 1977.

da ABEn Central (REBEn e BI). Entretanto apenas a Seção SP-São Paulo estabeleceu o sistema de distribuição nas residências; SP-Araraquara, $P R$ e RJVolta Redonda e RS optaram pela distribuição nas residências ou no local de trabalho. A Seção RJ-Niterói e Ribeirão Preto-SP, fazem a distribuição apenas nos locais de trabalho e as Seções CE, PB, DF e GO nos locais de trabalho e nas sedes. As Seções RJ e SC adotam as três alternativas. As demais Seções fazem a distribuição apenas na sede.

As Seções de SE, BA, RJ, SP-São Paulo, Ribeirão Preto e Araraquara distribuem o BI ou jornal da Seção. Este Distrito, o de Juiz de Fora-MG e o DF distribuem circulares das Seções.

As Seções do MA, RN, BA, PR e GO promoveram a publicação de trabalhos das associadas. As Seções do PA, BA, RJ-Niterói, PR, SC, RS, MG, DF e GO deram orientação às associadas sobre seus direitos e deveres. A Seção de SP promoveu a concessão de estudos e a co CE promoveu venda de livros. As Seções do PA, MA e RN promoveram cursos de atualização para as associadas. A Seção do RS divulgou informaçōes sobre Congressos e bolsas de estudos e faculta aos associados o uso de sua biblioteca.

\section{PERSPECTIVAS DE DESENVOLVIMENTO DAS SEÇÖES}

De acordo com o novo Estatuto, as Seções que contam com Distritos no interior do Estado devem constituir um Distrito na Capital, passando a Diretoria da Seção a preocupar-se principalmente em coordenar a ação dos vários Distritos e em fomentar seu desenvolvimento.

Até o momento, a Seção RJ foi a única a regularizar esta situação. As outras Seções que têm Distritos no interior são SP (Ribeirão Preto, Campinas, Santos e Araraquara), PR (Londrina), MG (Juiz de Fora), GO (Rio Verde), RS (Santa Maria e Caxias). Entretanto, as Seções SP e PR não realizaram Assembléias Estaduais de Delegados.

O número mínimo de associados para que seja criado um novo Distrito é, de agora em diante. de quarenta associados. No momento apenas os Distritos do Rio, Niterói, Ribeirão Preto e Juiz de Fora contam com um número de associados igual ou superior a este.

$A$ anuidade cobrada pela Seção PB e pelos Distritos de Volta Redonda-RJ e PR-Curitiba e Londrina é de $200 \mathrm{cru}$ zeiros. Os Distritos do Rio, RJ-Niterói, Juiz de Fora-MG e Rio Verde-GO cobram de 220 e 240 cruzeiros. SP, RS, MG e DF cobram de 300 a 360 cruzeiros. Todas pagam 100 cruzeiros "per capita" à ABEn Central. Entretanto o "per capita" pago pelos Distritos à Seção varia de zero a cinqüenta cruzeiros. Esta situação deverá ser corrigida a fim de possibilitar às Seções a criação dos Distritos da Capital, do contrário poderão ficar com renda insuficiente para desenvolver suas atividades.

Das necessidades sentidas pelas Seções para o seu desenvolvimento, o MA, CE, RN, BA. RJ-Niterói, PR e MG citaram o aumento do número de associados.

As Seções do CE, AL, RJ-Volta Redonda, SC e DF mencionaram maiores recursos humanos e/ou materiais e/ou financeiros.

As Seçōes de AL, BA, RJ-Niteról, SP, PR, RS, MG e GO citaram melhor coordenação entre a ABEn Central e as Seções, agilização das Diretorias, maior participação dos associados ou maior envolvimento das Escolas de Enfermagem na vida associativa. A Seção RJ citou a elaboração do Regimento Interno do Distrito.

No que se refere a instalações, a Seção do MA, CE, RN, PB, AL, SE. RJVolta Redonda, SP-Ribeirão Preto, SC e DF julgam prioritária a aquisição da 
CASTRO, I.B. - Relatório referente ao $1 .^{\circ}$ período de gestão 1976/80 (19/8/76 a 30-6-77).

Rev. Bras. Enf.; DF, $30: 356-369,1977$.

sede própria. As Seções do PA, CE, RN, PB, AL, SP-Ribeirão Preto e Araraquara, SC, RS e DF necessitam adquirir telefone. PA, AL, SE, SP-Ribeirão Preto, DF e MG necessitam de máquina de escrever, CE, PB, RJ-Rio, SP-Ribeirão Preto, PR, RS, MG-Belo Horizonte e Juiz de Fora e GO necessitam de copiadora (duplicadora), MA, PI, RN, PB, AL, SE, SP-Ribeirão Preto, Araraquara, SC e DF necessitam adquirir mobiliário. A Seção da BA deseja adquirir projetor de "slides" e quadro magnético. As Seções RJ e RS desejam adquirir nova sede, e a de GO deseja uma sede campestre.

A consulta da ABEn Central sobre o que seria necessário para a implantação de um sistema de orçamento-programa nas Seções, a do PA, CE, RN, AL e SE mencionaram recursos humanos e/ou financeiros. As do MA, BA, RJ-Rio, Niterói, $P R, D F$ e GO mencionaram orientação da ABEn Central.

Como sugestōes à ABEn Central, MA, $\mathrm{CE}, \mathrm{AL}$ e DF citaram ajuda financeira desta às Seçōes, seja relacionada ao "per capita", seja através de financimento ou ajuda aos delegados.

CE, AL, SE, MG e DF apresentaram sugestōes relcionadas a uma maior atenção da ABEn Central às Seçōes. RN sugere um programa de divulgação e que seja estudada a situação dos Distritos. MA ofereceu-se para organizar o Congresso Brasileiro de Enfermagem em 1980.

Das sugestões apresentadas, depreende-se o desejo de maior aproximação entre as Seçōes e a ABEn Central. Entretanto, a situação dos Distritos não parece bem definida. As relações entre os Distritos e a respectiva Seção e entre os Distritos e a ABEn Central são motivo de perplexidades. $O$ assunto revestese da maior importância, pois do desenvolvimento da vida associativa nos núcleos constituídos pelos Distritos depende a expansão da ABEn. $O$ espírito da determinação contida no novo Estatuto, de que sejam criados Distritos nas Capitais, é exatamente o de possibilitar às Diretorias das Seções dedicarem-se a tal mister.

Não obstante, ao término da elaboração desta sintese das atividades da ABEn a impressão que persiste é de vitalidade. Muitas novas tendências estão se definindo e as respostas das Diretorias têm sido bastante criativas, o que nos permite olhar para o futuro confiantes $e$ otimistas.

(As.) Ieda Barreira e Castro Presidente da ABEn 